\title{
Decreased Gray Matter Concentration in the Lateral Geniculate Nuclei in Human Amblyopes
}

\author{
Gareth R. Barnes, ${ }^{1}$ Xingfeng Li, ${ }^{2}$ Benjamin Thompson, ${ }^{2}$ Krishna D. Singh, ${ }^{3}$ \\ Serge O. Dumoulin, ${ }^{4}$ and Robert F. Hess ${ }^{2}$
}

Purpose. In a group of humans with strabismic amblyopia, the relationship was examined between the structure and function of different brain regions. Three question were addressed: (1) Is the lateral geniculate nucleus (LGN) in humans with amblyopia structurally as well as functionally abnormal? (2) Do structural anomalies in the visual cortex correlate with the previously reported cortical functional losses? (3) Is there a link between the functional anomalies in the visual cortex and any structural anomalies in the geniculate?

MeTHoDs. The structure was compared by using voxel-based morphometry (VBM) and the function by functional magnetic resonance imaging (fMRI).

RESults. The results showed that the geniculate is structurally abnormal in humans with strabismic amblyopia.

Conclusions. These findings add further weight to the role of the LGN in the cortical deficits exhibited in human strabismic amblyopes. (Invest Ophthalmol Vis Sci. 2010;51:1432-1438) DOI:10.1167/iovs.09-3931

mblyopia is a condition in which the vision through one
eye is permanently reduced due to a disruption in early
visual development. This disruption can be loss of form vision
(deprivation amblyopia), loss of focus (anisometropic amblyo-
pia), or loss of ocular alignment (strabismic amblyopia). Elec-
trophysiological studies in humans ${ }^{1,2}$ and single-cell studies in
animals made artificially amblyopic ${ }^{3-5}$ suggest that the site of
the deficit is not in the retina. Morphologic changes have been
reported in the layers of the lateral geniculate nucleus (LGN)
that receive input from the deprived eye in animals ${ }^{6-9}$ and
humans, ${ }^{10,11}$ although the functional properties of these cells
have been considered to be normal ${ }^{12,13}$ in most animal studies.
On the basis of these single-cell findings, it has been concluded
that the site of the amblyopic deficit is in the input layers of the
primary visual cortex. ${ }^{14}$ However, there is a body of literature
comprising studies in which functional anomalies have been
reported in the LGN of deprived animals. These range from

From the ${ }^{1}$ Wellcome Trust Centre for Neuroimaging, Institute of Neurology, London, United Kingdom; the ${ }^{2}$ McGill Vision Research Unit, Department of Ophthalmology, McGill University, Montreal, Quebec, Canada; the ${ }^{3}$ CUBRIC (Cardiff University Brain Research Imaging Center), School of Psychology, Cardiff University, Cardiff, United Kingdom; and the ${ }^{4}$ Helmholtz Institute, Experimental Psychology, Utrecht University, Utrecht, The Netherlands.

Supported by CIHR (Canadian Institutes of Health Research) Grant MOP-53346 and the Lord Dowding Foundation (GRB).

Submitted for publication April 29, 2009; revised August 18 and September 22, 2009; accepted September 23, 2009.

Disclosure: G.R. Barnes, None; X. Li, None; B. Thompson, None; K.D. Singh, None; S.O. Dumoulin, None; R.F. Hess, None

Corresponding author: Robert F. Hess, McGill University, 687 Pine Avenue, W (H4-14), Montreal H3A 1A1, Quebec, Canada;

robert.hess@mcgill.ca. selective deficits in X-cells, ${ }^{15}$ selective deficits in Y-cells, ${ }^{16}$ and more diffuse deficits in all cells. ${ }^{8}$ Furthermore, a case study ${ }^{17}$ suggested a functional magnetic resonance deficit at the level of the LGN in humans with anisometropic amblyopia. More recently, it has been shown that the functional responses are reduced at the level of the geniculate in humans with strabismic, anisometropic, and deprivation amblyopia ${ }^{18}$ and that this deficit may be selective for P-cell function. ${ }^{19,20}$

The reduced geniculate response when driven by the amblyopic eye may in principle be due to a reduced input from the eye, anomalous geniculate function per se, or aberrant feedback signals from the primary visual cortex. To better understand the basis for the reduced geniculate response reported in humans with amblyopia, we undertook a structural study of the geniculate to answer the following questions: First, is the LGN in humans with amblyopia structurally as well as functionally abnormal? This question relates to whether the previously reported response reduction ${ }^{17-20}$ is due to reduced geniculate function per se or to a reduction in either the feedforward drive from the retina or the feedback drive from the cortex. Second, do structural anomalies in the visual cortex correlate with the previously reported cortical functional losses? This question relates to whether the previously reported cortical structural losses ${ }^{21,22}$ have any functional significance, as one might expect from a simple cellular loss hypothesis that explains the functional deficit. And finally, is there a link between the functional anomalies in the visual cortex and any structural anomalies in the geniculate? This question relates to whether any structural deficit in the geniculate is of fundamental importance to the cortical processing deficit in amblyopia or whether it is just an epiphenomenon.

\section{Methods}

\section{Stimuli}

The stimuli in this experiment were conventional retinotopic wedge and annulus checkerboard sections used for retinotopic mapping. ${ }^{23,24}$ The abruptly alternating radial square-wave checkerboard had a fundamental temporal frequency of $8 \mathrm{~Hz}$. The fundamental circumferential spatial frequency of the checks varied from $1.0 \mathrm{cyc} / \mathrm{deg}$ centrally to $0.1 \mathrm{cyc} / \mathrm{deg}$ peripherally. Both stimuli completed a full cycle in 12 time frames $(0.03 \mathrm{~Hz})$, giving a total of six cycles per scanning run. The checkerboard had a contrast of $80 \%$. The wedge subtended $90^{\circ}$. The radial checkerboard contained 20 radial spokes, 10 concentric bands, and subtended a visual angle of $34^{\circ}$. The subject was instructed to attend to a central fixation point. ${ }^{25}$ The mapping stimulus was viewed alternately with each eye, the other eye being patched.

Stimuli were presented in a phase-encoded paradigm, always alternating runs between the left and right eyes of normal subjects or the fixing and amblyopic eyes of amblyopic subjects, while the subject attended to a central fixation spot and performed a visual task designed to control for attention. This task involved the detection of a coherent patch of checkerboard within the checkerboard stimulus as a whole 
that appeared at random times and positions. The responses were recorded via an optically isolated mouse. This task maintained the subject's attention at an engaged and constant state throughout the scans. In two previous studies using this stimulus, we have shown that amblyopes can maintain central fixation ${ }^{25}$ and that any fixation instability does not correlate with reduced BOLD (blood-oxygen-leveldependent) response. ${ }^{26}$

We identified retinotopic visual areas by using the methods of Dumoulin et al. ${ }^{27}$ A 1.5-T scanner (Sonata; Siemens Medical Systems, Erlangen, Germany) was used to collect both anatomic and functional images. Anatomic images were acquired by using a head coil (circularly polarized transmit and receive) and a $\mathrm{T}_{1}$-weighted sequence (TR, 22 $\mathrm{ms}$; TE, $10 \mathrm{~ms}$; flip angle, $30^{\circ}$ ) of 180 sagittal slices of $256 \times 256$ image voxels were acquired that provided a voxel size of $1 \mathrm{~mm}^{3}$. Functional scans for each subject were collected via a surface coil (circularly polarized, receive only) positioned beneath the subject's occiput. Each functional imaging session was preceded by a surface coil anatomic scan (identical with the head coil anatomic sequence, except that the number of sagittal slices was reduced to 80 with a resolution of $256 \times$ 256 and a slice thickness of $2 \mathrm{~mm}$ ), to co-register the data later with the head-coil image. Functional scans were multislice $\mathrm{T}_{2}{ }^{*}$-weighted, gradient-echo, planar images (GE-EPI; TR, 3.0 seconds; TE, $51 \mathrm{~ms}$; flip angle, $90^{\circ}$ ). Image volume consisted of 30 slices orthogonal to the calcarine sulcus. The field of view was $256 \times 256 \mathrm{~mm}$, the matrix size was $64 \times$ 64 with a thickness of $4 \mathrm{~mm}$, giving voxel sizes of $4 \times 4 \times 4 \mathrm{~mm}$. Each experiment consisted of four acquisition runs for each eye (two eccentricity runs, two polar angle runs). Eccentricity runs consisted of both expanding and contracting directions and polar angle runs consisted of both clockwise and counterclockwise directions. Each run consisted of 128 image volumes acquired at 3-second intervals (TR). Fixing and amblyopic eye information was averaged separately across the two eccentricity runs and across the two polar angle runs. Runs were alternated between the eyes in each case.

We used software developed at the Montreal Neurologic Institute (http://www.bic.mni.mcgill.ca/software/) to estimate gray and white matter densities. For each anatomic image, we corrected for intensity variation $^{28}$ and transformed the image into standard stereotaxic space. $^{29,30}$ We used a nonparametric classification algorithm that incorporates prior tissue probability maps in standard space to label each voxel as gray or white matter or cerebrospinal fluid (CSF). ${ }^{31} \mathrm{Next}$, we extracted the three binarized images corresponding to gray matter, white matter, or CSF, which were in each case premultiplied by a whole-brain template, to remove skull and scalp artifacts. These normalized images were then smoothed with an isotropic 6-mm full width at half-maximum (FWHM) Gaussian kernel. Within an individual gray matter image therefore, every point in space corresponded to a weighted local (within the nearby $6 \mathrm{~mm}$ ) gray matter concentration estimate. $^{32}$ Asburner and Friston ${ }^{32}$ point out that such estimates should not be confused with cytoarchitechtonic cell-packing density, as the value of the concentration will be determined by both structure (e.g., local cortical curvature ${ }^{33}$ and density). That is, the metric is dimensionless and quantifies the number of local voxels classified as gray ranging from 0 to 1.0 in regions where all surrounding voxels are classified as gray.

To compare anatomy across subjects, we used both standardized and individual anatomic templates. We used standard space templates for the occipital and temporal lobes as well as a region defining the LGN. The template lobes were created using mri3dX (http://cubric. psych.cf.ac.uk/Documentation, provided in the public domain by University of Cardiff, Wales, UK). The LGN templates were constructed based on published stereotaxic coordinates. ${ }^{34}$ Based on anatomic scans, the estimates of Kastner et al. ${ }^{34}$ estimates of LGN location ( \pm SD) are $22.88 \pm 1.8,-21.3 \pm 1.49$, and $-4.63 \pm 2.13$ and $-23.33 \pm 1.41$, $-21 \pm 1.6,-4.66 \pm 1.33 \mathrm{~mm}$ for the right and left LGN, respectively. Postmortem data from Andrews et al. ${ }^{35}$ suggest that the LGN (parvo plus magno, across left and right structures) volume in humans is $118.5 \pm 19.5 \mathrm{~mm}^{3}$, when approximating the LGN as a cube gives a mean side length of $4.89 \pm 0.27 \mathrm{~mm}$. This closely accords with anatomic MRI estimates from Gupta et al. ${ }^{36}$ of $4.74 \pm 0.54$ and $4.83 \pm$ $0.95 \mathrm{~mm}$ for right and left LGN, respectively. Taking the mean SD across all dimensions gives $1.62 \mathrm{~mm}$ (i.e., 95\% of all LGNs will be centered within approximately $3.24 \mathrm{~mm}$ of these locations). Approximating the LGN as a cube with a side length of $5 \mathrm{~mm}$, to fit this variability we must accommodate $5+3.24 \cdot 2 \mathrm{~mm}$ in each dimension within the template. With this location variability in mind, we constructed two anatomic templates of different cubic volume $(5 \times 5 \times 5$ and $12 \times 12 \times 12 \mathrm{~mm}$ ) both centered on the mean locations from Kastner et al. ${ }^{34}$ Unless otherwise stated, all results shown are for the 12-mm cubic template.

To rigorously test whether the differences observed between the control and amblyopic subjects were due to chance, we constructed 100 randomly placed pseudo-LGN structural templates. These templates were the same size as the original anatomic templates (5- or 12-mm cube side) and were also symmetrically placed about the midline by randomly selecting a cube within the right hemisphere and mirroring it to the left.

For each individual, we also constructed individual anatomic templates based on the retinotopic maps (V1,V2, V3, VP, V3A, and hV4) defined from the functional retinotopy scans. For each template, we calculated the total gray matter by simply multiplying the smoothed binary classified images by the binary template volume and averaging the image values remaining.

The retinotopy scans also yielded BOLD signal change measures for each eye (published elsewhere ${ }^{25}$ ). fMRI time series were normalized, and the design matrix for the general linear model was constructed by means of the inverse Fourier transformation. ${ }^{26} \mathrm{~A}$ first-order autoregressive model was used to fit the temporal correlation and then, the mean squares of regression (MSR) and errors (MSE) were calculated, where MSR constitutes the amount of variance predicted by the model and MSE the unexplained variance. BOLD signal activation was quantified by means of an $F$ ratio where $F=$ MSR/MSE. ${ }^{37}$ We then computed Spearman rank correlations between the amount of LGN gray matter and the difference in $F$ value between eyes $\left(F_{\text {good }}-F_{\text {bad }}\right)$. We also tested whether the functional difference observed within a visual area could be explained by the amount of gray matter within that same area.

\section{Subjects}

The subjects in this experiment have already been described elsewhere. ${ }^{25}$ In brief, there were 16 amblyopes. All had strabismus, but only some $(n=6)$ also had associated anisometropia. The average age of the amblyopes was $37.9 \pm 13.6(\mathrm{SD})$ years. The clinical details of 11 of these subjects have already been reported but are given for completeness in Table 1 . The remaining five subjects' clinical data are given at the bottom of Table 1, indicated by asterisks. All subjects were optically refracted and wore their full correction during testing. In addition to the amblyopic subjects, 11 normal control subjects were scanned as part of the 2007 study. ${ }^{25}$ These all had corrected visual acuity better than 20/25 and an average age of $34 \pm 5$ ) years. All studies were performed with the informed consent of participants, were approved by the Research Ethics board of the Montreal Neurologic Institute, and adhered to the tenets of the Declaration of Helsinki.

\section{Results}

To answer the three questions posed in the introduction, we undertook a structural analysis of normal and amblyopic brains by using voxel-based morphometry (VBM). ${ }^{38}$ We performed two comparisons: the brains of normal and amblyopic persons as well as the correlation between the cortical function (fMRI) and brain structure (VBM) in a group of 16 amblyopes and 11 normal subjects.

\section{Is the LGN in Humans with Amblyopia Structurally as Well as Functionally Abnormal?}

Our main finding was that there was significantly (LGN size 12 , Wilcoxon's sign rank test, $z=2.1 ; P<0.04$, two-tailed) less 
TABLE 1. Clinical Details of Subjects

\begin{tabular}{|c|c|c|c|c|c|c|}
\hline Subj. & Age/Sex & Type & Refraction & Acuity & Squint & History \\
\hline DV & $23 / \mathrm{F}$ & LE mixed & $\begin{array}{l}+0.25 \mathrm{DS} \\
+2.75-1.25 \times 175^{\circ}\end{array}$ & $\begin{array}{l}20 / 20 \\
20 / 40\end{array}$ & ET $3^{\circ}$ & $\begin{array}{l}\text { Detected at age } 5-6 \mathrm{y} \text {, patching for } 6 \\
\text { mo; no surgery }\end{array}$ \\
\hline $\mathrm{EF}$ & $56 / \mathrm{M}$ & LE strab & $\begin{array}{l}+2.00+1.00 \times 180^{\circ} \\
+2.00+1.00 \times 130^{\circ}\end{array}$ & $\begin{array}{l}20 / 32 \\
20 / 250\end{array}$ & ET $6^{\circ}$ & $\begin{array}{l}\text { Detected at age } 6 \mathrm{y} \text {, patching for } 1-2 \\
\mathrm{y} \text {, no surgery }\end{array}$ \\
\hline GN & $30 / \mathrm{M}$ & RE mixed & $\begin{array}{l}+5.00-2.00 \times 120^{\circ} \\
+3.50-1.00 \times 75^{\circ}\end{array}$ & $\begin{array}{l}20 / 70 \\
20 / 20\end{array}$ & ET $8^{\circ}$ & $\begin{array}{l}\text { Detected at age } 5 \mathrm{y} \text {, patching for } 3 \mathrm{mo} \text {, } \\
\text { no glasses tolerated, } 2 \text { strabismus } \\
\text { surgeries RE age } 10-12 \mathrm{y}\end{array}$ \\
\hline HP & $33 / \mathrm{M}$ & LE strab & $\begin{array}{l}+0.50 \mathrm{DS} \\
+0.50 \mathrm{DS}\end{array}$ & $\begin{array}{l}20 / 25 \\
20 / 63\end{array}$ & ET $5^{\circ}$ & $\begin{array}{l}\text { Detected at age } 4 \mathrm{y} \text {, patching for } 6 \mathrm{~m} \text {; } \\
\text { surgery at } 5 \mathrm{y}\end{array}$ \\
\hline LM & $20 / \mathrm{F}$ & RE mixed & $\begin{array}{l}+1.0-0.75 \times 90^{\circ} \\
-3.25 \mathrm{DS}\end{array}$ & $\begin{array}{l}20 / 80 \\
20 / 25\end{array}$ & ET $6^{\circ}$ & Detected at age $5 \mathrm{y}$, patching for $2 \mathrm{y}$ \\
\hline MB & $50 / \mathrm{M}$ & RE strab & $\begin{array}{l}-1.00 \mathrm{DS} \\
+1.00 \mathrm{DS}\end{array}$ & $\begin{array}{l}20 / 32 \\
20 / 80\end{array}$ & ET $3^{\circ}$ & No surgery, first glasses at $32 \mathrm{y}$ \\
\hline MG & $30 / \mathrm{F}$ & RE strab & $\begin{array}{l}-0.50 \mathrm{DS} \\
+0.50 \mathrm{DS}\end{array}$ & $\begin{array}{l}20 / 100 \\
20 / 15\end{array}$ & ET $1^{\circ}$ & $\begin{array}{l}\text { Detected at age } 4 \mathrm{y} \text {, patching for } 6 \mathrm{~m} \text {, } \\
\text { no surgery }\end{array}$ \\
\hline $\mathrm{OA}$ & $21 / M$ & RE mixed & $\begin{array}{l}+4.50-5.00 \times 30^{\circ} \\
-1.75 /-1.75 \times 150^{\circ}\end{array}$ & $\begin{array}{l}20 / 120 \\
20 / 32\end{array}$ & ET $5^{\circ}$ & $\begin{array}{l}\text { Detected at age } 3 \mathrm{y} \text {, drug and patching } \\
\text { at } 3 \mathrm{y} \text {, no surgery }\end{array}$ \\
\hline VE & $69 / \mathrm{M}$ & LE mixed & $\begin{array}{l}-1.75-1.75 \times 150^{\circ} \\
+4.5-5.00 \times 30^{\circ}\end{array}$ & $\begin{array}{l}20 / 25 \\
20 / 80\end{array}$ & ET $5^{\circ}$ & Detected at age $10 \mathrm{y}$, no treatment \\
\hline $\mathrm{XL}$ & $31 / \mathrm{F}$ & RE strab & $\begin{array}{l}-2.75+0.75 \times 110^{\circ} \\
-2.50 \text { DS }\end{array}$ & $\begin{array}{l}20 / 400 \\
20 / 20\end{array}$ & ET $15^{\circ}$ & Detected at age $13 \mathrm{y}$, no treatment \\
\hline YC & $31 / \mathrm{M}$ & LE strab & $\begin{array}{l}+2.00 \mathrm{DS} \\
+2.00 \mathrm{DS}\end{array}$ & $\begin{array}{l}20 / 15 \\
20 / 40\end{array}$ & ET $10^{\circ}$ & $\begin{array}{l}\text { Detected at age } 2 \mathrm{y} \text {, patching for } 4 \mathrm{y} \text {, } \\
\text { glasses for } 16 \mathrm{y}\end{array}$ \\
\hline $\mathrm{RD}^{*}$ & $49 / \mathrm{F}$ & LE strab & $\begin{array}{l}+3.25 \mathrm{DS} \\
+4.00 \mathrm{DS}\end{array}$ & $\begin{array}{l}20 / 15 \\
20 / 40\end{array}$ & XT $2^{\circ}$ & $\begin{array}{l}\text { Detected at age } 6 \mathrm{y} \text {, glasses since } 6 \mathrm{y} \text {, } \\
\text { no other treatment }\end{array}$ \\
\hline $\mathrm{AR}^{*}$ & $47 / \mathrm{M}$ & RE strab & $\begin{array}{l}\text { Plano } \\
\text { Plano }\end{array}$ & $\begin{array}{l}20 / 20 \\
20 / 50\end{array}$ & ET $1^{\circ}$ & $\begin{array}{l}\text { Detected at age } 6 \mathrm{y} \text {, no patching, no } \\
\text { surgery }\end{array}$ \\
\hline $\mathrm{GH}^{*}$ & $45 / \mathrm{M}$ & RE mixed & $\begin{array}{l}-1.25-0.5 \times 180^{\circ} \\
+1.25 \mathrm{DS}\end{array}$ & $\begin{array}{l}20 / 20 \\
20 / 63\end{array}$ & ET $6^{\circ}$ & $\begin{array}{l}\text { Detected at age } 10 \mathrm{y} \text {, patching for } 1 \mathrm{~m} \text {, } \\
\text { glasses for } 1 \mathrm{y}\end{array}$ \\
\hline $\mathrm{KS}^{*}$ & $40 / \mathrm{M}$ & RE strab & $\begin{array}{l}+5.00-1.00 \times 180^{\circ} \\
+0.50 \mathrm{DS}\end{array}$ & $\begin{array}{l}20 / 70 \\
20 / 20\end{array}$ & $\mathrm{XT} 4^{\circ}$ & $\begin{array}{l}\text { Detected at age } 10 \mathrm{y} \text {, patching for } 1 \mathrm{~m} \text {, } \\
\text { glasses for } 1 \mathrm{y}\end{array}$ \\
\hline $\mathrm{GJ}^{*}$ & $25 / \mathrm{F}$ & LE strab & $\begin{array}{l}-2.00 \mathrm{DS} \\
-2.00 \mathrm{DS}\end{array}$ & $\begin{array}{l}20 / 20 \\
20 / 100\end{array}$ & ET $3^{\circ}$ & Surgery at age $2 \mathrm{y}$, patching for $1 \mathrm{y}$ \\
\hline
\end{tabular}

Strab, strabismus; mixed, strab+aniso; RE, right eye; LE, left eye; ET, esotropia; XT, exotropia; DS, diopter sphere.

* Subjects not previously reported.

gray matter in the LGNs of the amblyopic group than in the control group (Fig. 1). For LGN size 12, the mean gray matter concentration in the amblyopic group was 0.5231 (SE 0.0197) and in the normal group, 0.6012 (SE 0.0308).

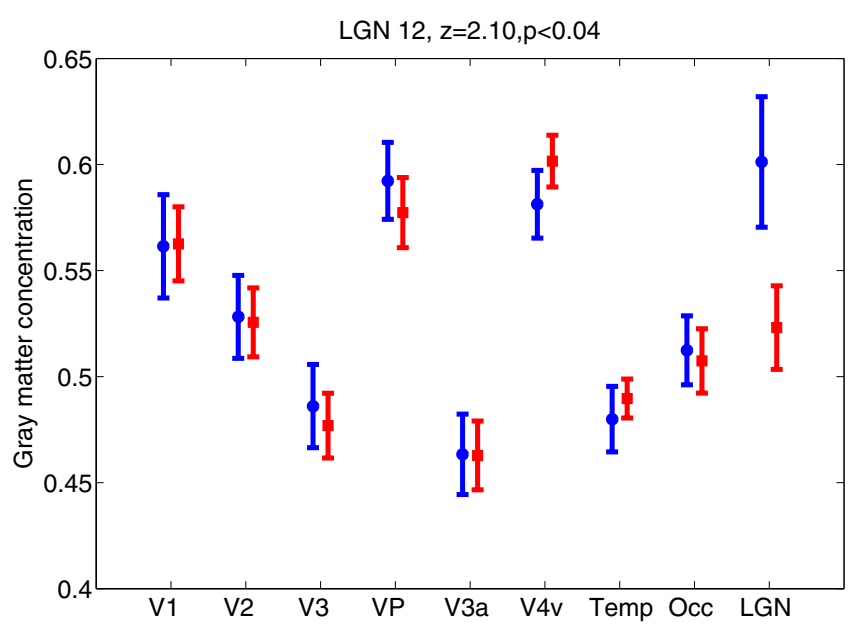

FigURE 1. Amount of gray matter for amblyopic (red squares) and control (blue circles) subjects across subject-specific, retinotopically defined visual areas and standard space anatomic templates for the occipital lobes, temporal lobes, and LGN (12-mm template). The amblyopic observers had significantly $(z=2.1, P<0.04)$ less gray matter within the LGN template. No gray matter differences were found within any other structure.
These results were found no matter which LGN template we used (for LGN size 5, $z=2, P<0.05$ ). For LGN size 5, the mean gray matter concentration in the amblyopic group was 0.5034 (SE 0.0202) and in the normal group, 0.5793 (SE $0.0320)$.

However, we did not find a difference in gray matter between the amblyopes and the control groups in any of the other visual areas identified or within the occipital or temporal lobes.

We were concerned that the differences observed at the LGN could be due to the relatively small generic anatomic template, which gave an anomalous result by chance. To more rigorously test this possibility, we produced 100 templates containing randomly but symmetrically placed masks of both sizes (either 5 or $12 \mathrm{~mm}$ ). The locations of these randomly chosen masks are shown in Supplementary Figure S1, http:// www.iovs.org/cgi/content/full/51/3/1432/DC1. Figure 2 shows the difference in gray matter within these masks (in the $12-\mathrm{mm}$ case) in the amblyopes compared with the control group. The distribution of differences obtained suggests that our results are unlikely to have arisen by chance $(P<0.01$ and $P<0.02$ for the 12- and 5-mm masks, respectively).

\section{Do Structural Anomalies in the Visual Cortex Correlate with the Previously Reported Cortical Functional Losses?}

Mendola et al. ${ }^{22}$ have suggested that amblyopes have less gray matter within their primary visual cortices (but, see the Discussion section). As our anatomic results did not support their 


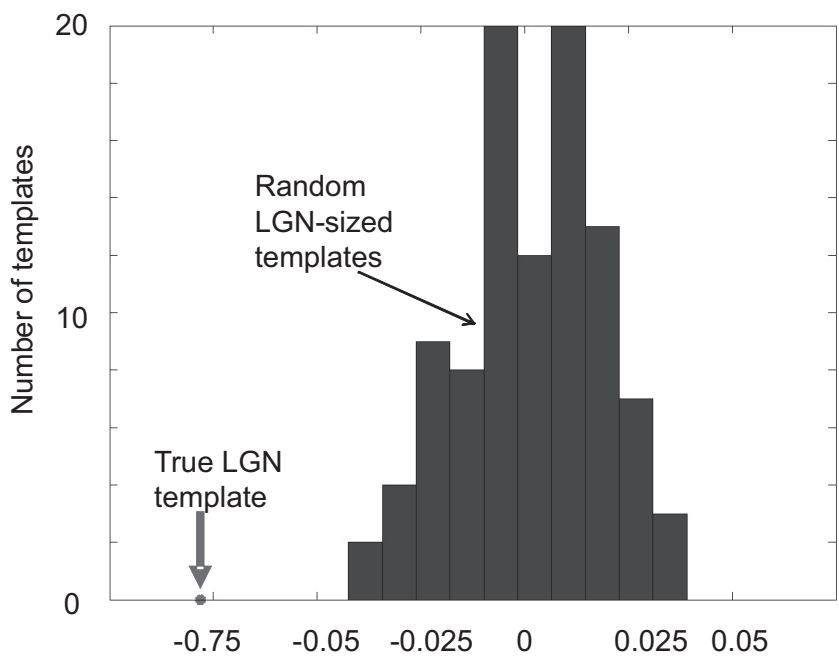

Difference (ambs-controls) in gray matter concentration

FiguRE 2. The gray matter difference between controls and amblyopes for 100 randomly generated pseudo-LGN structures (12-mm template) placed randomly within the right hemisphere and mirrored on the left. Dot: difference observed using the original anatomically defined (12-mm) template. That is, it is unlikely that the difference was due to chance $(P<0.01)$.

finding (Fig. 1), we went on to see whether the gray matter (within an area) could in some way explain the functional differences (between eyes) observed in that same area. Our main observation was a generally stronger (and positive) coupling between the functional difference and the gray matter within an area in the amblyopic group than in the control group (Table 2). Specifically, VP and V4 both showed significant positive correlations between functional difference and gray matter $(\rho=0.6, P<0.017 ; \rho=0.52, P<0.041$, respectively). In the $\mathrm{VP}$, this same significant result was observed across the cohort $(\rho=0.47, P<0.014)$. We also found that correlations in $\mathrm{V} 2$ and $\mathrm{V} 3$ in the amblyopic group fell short of significance $(P<0.068)$ for this two-tailed test (one-tailed $P<0.034)$. We found these results surprising: the more gray matter within an area, the larger the difference between amblyopic and fixing eye viewing one would expect to observe within that same area. This observation runs contrary to the idea that the functional deficits could be due to there being fewer cells.

\section{Is There a Link between the Functional Anomalies in the Visual Cortex and Any Structural Anomalies in the Geniculate?}

We were interested to see whether these gray matter differences in the LGN could explain any of the variation in cortical hemodynamic response observed between amblyopic and fixing, or dominant and nondominant, eyes. ${ }^{25}$ Figure 3 shows the functional difference between the two eyes observed in V1 as a function of the LGN gray matter across both the amblyopic and control groups. Table 3 shows the correlations between the difference in $F$ values (between fixing/dominant and amblyopic/nondominant eye viewing) and the amount of LGN gray matter across subjects. Combining data for amblyopic and normal subjects, the difference in activity in the primary visual cortex is significantly related to the amount of LGN gray matter in an individual $(\rho=-0.57, P<0.002$, two-tailed). With multiple-comparison correction (if one were to assume there are six independent tests) and with no prior hypothesis on the direction of the effect, the difference remains significant $(P<$ 0.01): put simply, the less LGN gray matter, the greater the fMRI V1 response of the dominant/fixing eye relative to the nondominant/amblyopic eye.

Essentially, this is the concatenation of the previously reported finding that amblyopes have smaller V1 activation for amblyopic versus fixing-eye viewing, ${ }^{39}$ coupled with the anatomic data presented in this article (amblyopes have less LGN gray matter). We also tried different metrics of functional difference, such as the contrast $\left[\left(F_{\text {good }}-F_{\text {bad }}\right) /\left(F_{\text {good }}+F_{\text {bad }}\right]\right)$ and the ratio $\left(F_{\text {good }} / F_{\text {bad }}\right.$ of $F$ values giving $\rho=-0.55 P<$ 0.004 and $\rho=-0.55, P<0.004$, respectively. (The values are identical, as the points remained in the same order.) For the 5-mm LGN template, these values were $\rho=-0.54, P<0.004$; $\rho=-0.52, P<0.006$; and $\rho=-0.52, P<0.006$ for difference, contrast, and ratio metrics, respectively.

\section{DisCussion}

In this study, we asked three questions, the first of which was, is the LGN in bumans with amblyopia structurally as well as functionally abnormal? We report structural anomalies in the lateral geniculate nuclei of humans with amblyopia. The finding that the geniculates of amblyopes differ structurally, having reduced gray matter concentration, from those of normal persons is novel but not unexpected, considering the animal literature on the structural anomalies in the layers receiving input from the deprived eye. ${ }^{6-9,40}$ It does suggest that the recent reports ${ }^{17-20}$ of reduced responses from the geniculates of amblyopes may be the result of reduced geniculate function, per se, and not a reflection of reduced feedforward input from the retina or reduced feedback drive from the cortex.

The second question posed was, do structural anomalies in the visual cortex correlate with the previously reported cortical functional losses? Although we did not observe any obvious structural differences between the occipital cortices of normal and amblyopic individuals, unlike previous reports, ${ }^{21,22}$ we did find a structure-function correlation in the visual areas VP and hV4 (the trends in V2 and V3 narrowly failed to reach significance). The correlations observed in the amblyopic but not the control group (Table 2, and see also the Supplementary Material, http://www.iovs.org/cgi/content/full/ 51/3/1432/DC1), however, suggest that the functional deficit is positively related to an increase in gray matter. This result is

TABLE 2. Cortical Functional Signals and Structural Correlation with the Cortical Areas

\begin{tabular}{lccrrrr}
\hline & V1 & V2 & V3 & VP & V3a & hV4 \\
\hline Corr amb & $0.42(0.109)$ & $0.47(0.068)$ & $0.47(0.068)$ & $\mathbf{0 . 6 0 ( 0 . 0 1 7 )}$ & $0.09(0.755)$ & $\mathbf{0 . 5 2 ( 0 . 0 4 1 )}$ \\
Corr norm & $0.07(0.839)$ & $0.21(0.539)$ & $-0.18(0.595)$ & $0.35(0.286)$ & $-0.55(0.082)$ & $-0.20(0.558)$ \\
Corr both & $0.32(0.107)$ & $0.36(0.064)$ & $0.18(0.359)$ & $\mathbf{0 . 4 7 ( 0 . 0 1 4 )}$ & $-0.09(0.657)$ & $0.29(0.141)$ \\
\hline
\end{tabular}

The correlation is between the gray matter and the functional difference observed within each visual area. The amount of gray matter in VP and $\mathrm{V} 4$ of the amblyopic group predicts the functional difference between eyes in these same areas. The more gray matter the larger the difference in activation due to the viewing eye. In VP this effect propogates to the whole cohort. Note also the large (but not significant) correlations in amblyopes between V2 and V3 gray matter and the functional difference within these areas. Significant correlations are in bold. 


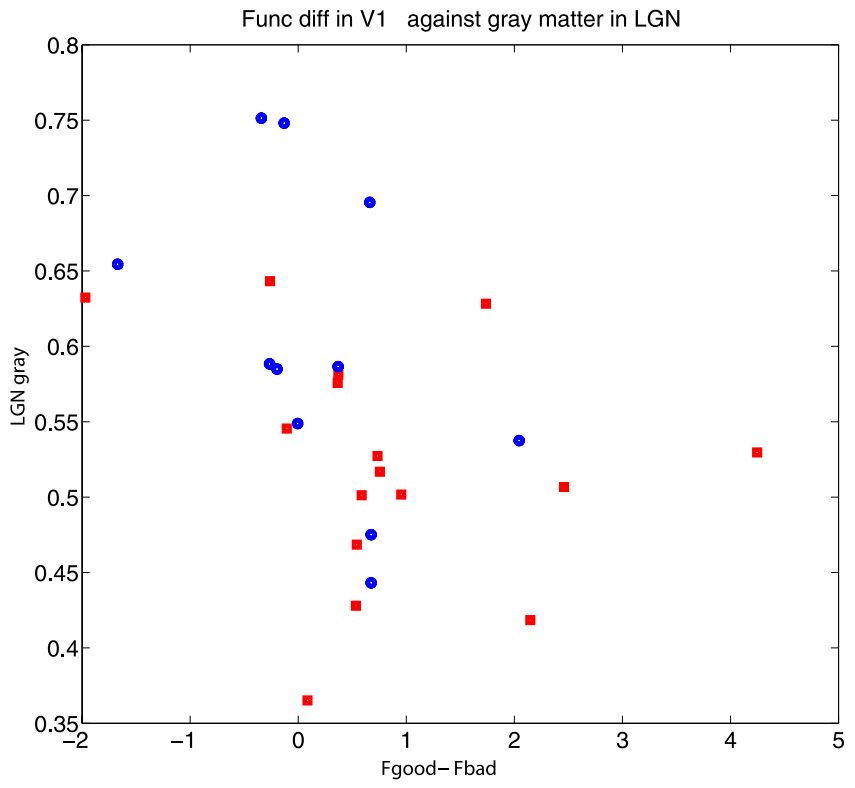

Figure 3. The functional difference observed in V1 between stimulation of good/dominant versus the deviating/nondominant eye as a function of the LGN gray matter across both amblyopic (red squares) and control (blue circles) groups. There was no significant correlation within either group as a function of LGN gray matter (Table 3). However, the cohort as a whole showed a significant correlation between the amount of LGN gray matter and the difference in V1 activity $(N=27, \rho=-0.57, P<0.002)$.

the opposite of that expected on the basis of a cellular loss hypothesis for the functional deficit. ${ }^{21,22}$ Rather than cellular loss, it would be consistent with a migration of cells from the amblyopic to the fixing eye-in other words, rather than loss of cells, a reassignment of cellular connections. In this case, a higher gray matter concentration would mean a larger BOLD response, which would effectively amplify the difference between the cell populations.

Finally, we asked, is there a link between the functional anomalies in the visual cortex and any structural anomalies in the geniculate? We found no significant relationship between the response magnitude due to stimulation from either eye in the visual cortex and the LGN structure in either the amblyopic or control group (with the exception of a possible relationship between $\mathrm{hV} 4$ function and LGN structure in the amblyopes; Table 3). We did find, however, a significant correlation across the whole cohort (amblyopes and control subjects) between the structure of the geniculate and the difference in hemodynamic response between eyes (see Fig. 3, Table 3). This correlation is certainly driven by the fact that normal subjects have more gray matter in their LGNs than do amblyopic ones and that amblyopes have larger functional deficits-hence, the less LGN gray matter, the larger the functional deficit.

Put together, these findings add structural evidence to the already accumulating functional evidence ${ }^{17-20,41}$ that the LGN plays a fundamental part in the processing deficit that has been attributed to the visual cortex of amblyopic humans. ${ }^{26,39,42,43}$ Recent animal studies ${ }^{44}$ have also shown that the LGN plays a fundamental role in the cortical deficits that develop as a consequence of different forms of visual deprivation. It is still unclear whether functional and structural deficits in the LGN are primary or secondary to the cortical deficit. Since the first level at which excitatory combination between the two eyes occurs is at the level of the primary visual cortex (layers 4-6), the most likely explanation is that the geniculate effects are secondary (i.e., via feedback from layer 6) to an initial binocular competitive imbalance in the striate cortex.

The main difference between our findings and those in previous work $^{21,22}$ is that we did not see any reduction in gray matter within the amblyopic visual cortex (Fig. 1). This observation is not inconsistent with that of Mendola et al. ${ }^{22}$ who reported similar findings in adults with strabismus. Even though they concluded that there was reduced gray matter in the visual cortex of amblyopic observers these differences were mainly evident in anisometropic children. However, our findings are at odds with those of Chan et al., ${ }^{21}$ who found reduced gray matter in the visual cortex of strabismic amblyopes and an increase in gray matter in other areas of the brain (including the subcortical structures). It should be noted, however, that our VBM procedure did not contain the modulation stage ${ }^{45}$ used in these studies to account for gray matter intensity changes due to the nonlinear spatial normalization stage-the distinction being that we effectively tested for regional differences in the concentration rather than volume of gray matter ${ }^{32}$ within the volumetric masks. Another possible reason could be that our visual area templates were functionally rather than anatomically defined, and it is possible that regions of suboptimal functional cortex were excluded from our definitions of the visual areas. That said, we found no significant differences in the sizes of any of the visual areas in the amblyopic compared with the control group, nor did we find differences in gray matter across the occipital lobe. Whether or not there is a gray matter deficit in V1, our results add an interesting dimension, in that we found no relationship between gray matter and the functional deficit (Table 2) in this area; rather, this deficit was predicted by LGN anatomy. Our study is novel, in that we directly compared both structure and function within the brains of human amblyopes and showed that there is a relationship between the functional loss in the cortex and the structure of the LGN, which has not been previously reported (see Fig. 3, Table 3).

There are several areas in which our study could be extended or improved. Although the ages of our amblyopic and control cohorts are not significantly different $(t=1.59, P<$ $0.0613, d f=26$ ), they are not perfectly matched. The discrepant ages are a concern, as studies ${ }^{45}$ have shown the dependence of gray matter volume on age. Of note, such effects of aging seem to be more prevalent in the cortex, such as the parietal lobes ${ }^{46}$ and prefrontal cortex,${ }^{47}$ with relative preservation of gray matter concentration within the thalami. ${ }^{45}$ Our results are therefore inconsistent with an explanation based

TABLE 3. Cortical Functional Signals and Structural Correlation with the LGN

\begin{tabular}{lcccccc}
\hline & V1 & V2 & V3 & VP & V3a & hV4 \\
\hline Corr amb $(n=16)$ & $-0.24(0.366)$ & $0.26(0.329)$ & $0.01(0.974)$ & $0.15(0.584)$ & $0.14(0.599)$ & $0.10(0.722)$ \\
Corr norm $(n=11)$ & $-0.45(0.169)$ & $0.13(0.707)$ & $0.20(0.553)$ & $0.05(0.874)$ & $0.28(0.397)$ & $\mathbf{0 . 6 0 ( 0 . 0 5 0 )}$ \\
Corr both $(n=27)$ & $-\mathbf{0 . 5 7 ( 0 . 0 0 2 )}$ & $0.29(0.148)$ & $0.30(0.123)$ & $0.20(0.321)$ & $0.36(0.067)$ & $0.33(0.090)$ \\
\hline
\end{tabular}

Spearman's $\rho$ correlation coefficient (two-tailed significance level in parentheses) between the difference (between dominant and nondominant, or fixing and amblyopic eyes) in fMRI signal in each visual area and LGN gray matter across subjects. Significant correlations are in bold. 
purely on age, as we found no changes in gray matter concentration anywhere except the LGN (Fig. 1).

The main limitation of this study is our definition of LGN volume, which is based on previously published work in which functional localizers were used. ${ }^{34,48}$ The interindividual variability in size and location (although small) of the LGN may well have masked some effects. Future work might include an LGN localizer scan in each subject. Ideally, this scan would be high-resolution anatomic, as a functional LGN localizer may be suboptimal if LGN function is compromised. ${ }^{48}$ Tractography ${ }^{49}$ could also be used to help reliably delineate the boundaries between the LGN and adjacent structures. Such precise information would allow one to address whether LGN size or gray matter density (or both) contribute to the observed decreases in gray matter concentration in amblyopes.

\section{References}

1. Hess RF, Baker CL. Assessment of retinal function in severely amblyopic individuals. Vision Res. 1984;24:1367-1376.

2. Hess RF, Baker CL. Human pattern-evoked electroretinogram. J Neurophysiol. 1984;51:939-951.

3. Cleland BG, Crewther DP, Crewther SG, Mitchell DEM. Normality of spatial resolution of retinal ganglion cells in cats with strabismic amblyopia. J Physiol (Lond). 1982;326:235-249.

4. Cleland BG, Mitchell DEM, Gillard-Crewther S, Crewther DP. Visual resolution of ganglion cells in monocularly-deprived cats. Brain Res. 1980;192:261-266.

5. Crewther DP, Crewther SG, Cleland BG. Is the retina sensitive to the effects of prolonged blur? Exp Brain Res. 1985;58:427-434.

6. Einon G, Ikeda H, Tremain KE. Perikaryal size of cells in the lateral geniculate nucleus and amblyopia in cats reared with convergent squint (proceedings). J Physiol. 1978;278:50P.

7. Guillery RW. Binocular competition in the control of geniculate cell growth. J Comp Neurol. 1972;144:117-129.

8. Levitt JB, Schumer RA, Sherman SM, Spear PD, Movshon JA. Visual response properties of neurons in the LGN of normally reared and visually deprived macaque monkeys. J Neurophysiol. 2001;85: 2111-2129.

9. Tremain KE, Ikeda H. Relationship between amblyopia, LGN cell "shrinkage" and cortical ocular dominance in cats. Exp Brain Res. 1982; $45: 243-252$.

10. von Noorden GK, Crawford ML. The lateral geniculate nucleus in human strabismic amblyopia. Invest Ophthalmol Vis Sci. 1992;33: 2729-2732.

11. von Noorden GK, Crawford ML, Levacy RA. The lateral geniculate nucleus in human anisometropic amblyopia. Invest Ophthalmol Vis Sci. 1983;24:788-790.

12. Derrington AM, Hawken MJ. Spatial and temporal properties of cat geniculate neurones after prolonged deprivation. J Physiol (Lond). 1981;314:107-120.

13. Gillard-Crewther S, Crewther JP. Neural site of strabismic amblyopia in cats; x-cell acuities in the LGN. Exp Brain Res. 1988;73: 503-509.

14. Blakemore C, Vital-Durant F. Effects of visual deprivation on the development of the monkey's lateral geniculate nucleus. J Physiol (Lond). 1986;380:493-511.

15. Ikeda H, Tremain KE, Einon G. Loss of spatial resolution of lateral geniculate nucleus neurones in kittens raised with convergent squint produced at different stages of development. Exp Brain Res. 1978;31:207-220.

16. Sherman SM, Wilson JR, Guillery RW. Evidence that binocular competition affects the postnatal development of Y-cells in the cat's lateral geniculate nucleus. Brain Res. 1975;100:441-444.

17. Miki A, Liu GT, Goldsmith ZG, Liu CS, Haselgrove JC. Decreased activation of the lateral geniculate nucleus in a patient with anisometropic amblyopia demonstrated by functional magnetic resonance imaging. Ophthalmologica. 2003;217:365-369.

18. Hess RF, Thompson B, Gole G, Mullen KT. Reduced responses in the LGN of human amblyopes revealed by high field strength MRI. Eur J Neurosci. 2009;29(5):1064-1070.
19. Hess RF, Thompson B, Gole G, Mullen KT. The LGN deficit in amblyopia is selective for parvocellular function. Paper presented at: Meeting of the Society for Neuroscience; November 2008; Washington, DC.

20. Miki A, Siegfried J, Liu C-S, Modestino EJ, Liu G. Magno- and parvocellular visual cortex activation in anisometropia, as studied with functional magnetic resonance imaging. Neuroophthalmology. 2008;32:187-193.

21. Chan ST, Tang KW, Lam KC, Chan LK, Mendola JD, Kwong KK. Neuroanatomy of adult strabismus: a voxel-based morphometric analysis of magnetic resonance structural scans. Neuroimage. 2004;22:986-994.

22. Mendola JD, Conner IP, Roy A, et al. Voxel-based analysis of MRI detects abnormal visual cortex in children and adults with amblyopia. Hum Brain Mapp. 2005;25:222-236.

23. Engel SA, Rumelhart DE, Wandell BA, et al. fMRI of human visual cortex. Nature. 1994;369:525.

24. Sereno MI, Dale AM, Reppas JB, et al. Borders of multiple visual areas in humans revealed by functional magnetic resonance imaging. Science. 1995;268:889-893.

25. Li X, Dumoulin SO, Mansouri B, Hess RF. The fidelity of the cortical retinotopic map in human amblyopia. Eur J Neurosci. 2007;25: $1265-1277$

26. Li X, Dumoulin SO, Mansouri B, Hess RF. Cortical deficits in human amblyopia: their regional distribution and their relationship to the contrast detection deficit. Invest Ophthalmol Vis Sci. 2007;48: 1575-1591.

27. Dumoulin SO, Hoge RD, Baker CL, Hess RF, Achtman RL, Evans AC. Automatic volumetric segmentation of human visual retinotopic cortex. Neuroimage. 2003;18:576-587.

28. Sled JG, Zijdenbos AP, Evans AC. A non-parametric method for automatic correction of intensity non-uniformity in MRI data. IEEE Trans Med Imag. 1998;17:87-97.

29. Collins DL, Neelin P, Peters TM, Evans AC. Automatic 3D intersubject registration of MR volumetric data in standardized Talairach space. J Comput Assist Tomogr. 1994;18:192-205.

30. Talairach J, Tournoux P. Co-planar Stereotaxic Atlas of the Human Brain. New York: Thieme; 1988.

31. Cocosco CA, Zijdenbos AP, Evans AC. A fully automatic and robust brain MRI tissue classification method. Med Image Anal. 2003;7: 513-527.

32. Ashburner J, Friston KJ. Voxel-based morphometry: the methods. Neuroimage. 2000;11:805-821.

33. Hutton C, Draganski B, Ashburner J, Weiskopf N. A comparison between voxel-based cortical thickness and voxel-based morphometry in normal aging. Neuroimage. 2009;48(2):371-380.

34. Kastner S, O'Connor DH, Fukui MM, Fehd HM, Herwig U, Pinsk MA. Functional imaging of the human lateral geniculate nucleus and pulvinar. J Neurophysiol. 2004;91:438-448.

35. Andrews TJ, Halpern SD, Purves D. Correlated size variations in human visual cortex, lateral geniculate nucleus, and optic tract. J Neurosci. 1997;17:2859-2868.

36. Gupta N, Greenberg G, de Tilly LN, Gray B, Polemidiotis M, Yucel $\mathrm{YH}$. Atrophy of the lateral geniculate nucleus in human glaucoma detected by magnetic resonance imaging. BrJ Ophthalmol. 2009; 93:56-60.

37. Seber GAF, Lee AJ. Linear Regression Analysis. New York: WileyInterscience; 2003:97-118.

38. Wright IC, McGuire PK, Poline JB, et al. A voxel-based method for the statistical analysis of gray and white matter density applied to schizophrenia. Neuroimage. 1995;2:244-252.

39. Barnes GR, Hess RF, Dumoulin SO, Achtman RL, Pike GB. The cortical deficit in humans with strabismic amblyopia. $J$ Physiol (Lond). 2001;533:281-297.

40. Yin ZQ, Crewther SG, Wang C, Crewther DP. Pre- and post-critical period induced reduction of Cat-301 immunoreactivity in the lateral geniculate nucleus and visual cortex of cats Y-blocked as adults or made strabismic as kittens. Mol Vis. 2006;12:858-866.

41. Miki A, Liu GT, Modestino EJ, Bonhomme GR, Liu CS, Haselgrove JC. Decreased lateral geniculate nucleus activation in retrogeniculate hemianopia demonstrated by functional magnetic resonance imaging at 4 Tesla. Ophthalmologica. 2005;219:11-15. 
42. Conner IP, Odom JV, Schwartz TL, Mendola JD. Monocular activation of V1 and V2 in amblyopic adults measured with functional magnetic resonance imaging. J AAPOS. 2007;11:341-350.

43. Muckli L, Kiess S, Tonhausen N, Singer W, Goegel R, Sireteanu R. Cerebral correlates of impaired grating perception in individual psychophysically assessed human amblyopes. Vision Res. 2006;46: 506-526.

44. Linden ML, Heynen AJ, Haslinger RH, Bear MF. Thalamic activity that drives visual cortical plasticity. Nat Neurosci. 2009;12:390-392.

45. Good CD, Johnsrude IS, Ashburner J, Henson RN, Friston KJ, Frackowiak RS. A voxel-based morphometric study of ageing in 465 normal adult human brains. Neuroimage. 2001;14:21-36.
46. Resnick S, Goldszal A, Davatzikos C, et al. One-year age changes in MRI brain volumes in older adults. Cereb Cortex. 2000;10:464472 .

47. Raz N, Gunning FM, Head D, et al. Selective ageing of the human cerebral cortex observed in vivo: differential vulnerability of the prefrontal gray matter. Cereb Cortex. 1997;7:268-282.

48. Hess RF, Thompson B, Gole G, Mullen KT. Deficient responses from the lateral geniculate nucleus in humans with amblyopia. Eur J Neurosci. 2009;29:1064-1070.

49. Devlin JT, Sillery EL, Hall DA, et al. Reliable identification of the auditory thalamus using multi-modal structural analyses. Neuroimage. 2006;30:1112-1120. 